\title{
Perceptions of alcohol use in the context of HIV treatment: a qualitative study
}

This article was published in the following Dove Press journal: HIVIAIDS - Research and Palliative Care

\author{
Munyaradzi Madhombiro' \\ Bazondlile Marimbe-Dube' \\ Michelle Dube' \\ Malinda Kaiyo-Utete' \\ Angeline Paradzai ${ }^{2}$ \\ Dixon Chibanda' \\ Simbarashe Rusakaniko ${ }^{3}$ \\ ASJ van der Watt ${ }^{4}$ \\ Soraya Seedat ${ }^{4}$ \\ 'Department of Psychiatry, College \\ of Health Sciences, University of \\ Zimbabwe, Harare, Zimbabwe; \\ ${ }^{2}$ Department of Linguistics, University \\ of Zimbabwe, Harare, Zimbabwe; \\ ${ }^{3}$ Department of Community \\ Medicine, College of Health Sciences, \\ University of Zimbabwe, Harare, \\ Zimbabwe; ${ }^{4}$ Department of Psychiatry, \\ Stellenbosch University, Cape Town, \\ South Africa
}

Correspondence: Munyaradzi Madhombiro

University of Zimbabwe College of Health Sciences, Parirenyatwa Group of Hospital, Mazowe Road, Belgravia, Harare, Zimbabwe

Tel +263773064519

Emailmmadhombiro@gmail.com
Background: Alcohol use is associated with poor HIV treatment outcomes. This study aimed to understand patients' perceptions of the impact of alcohol use in the context of HIV care.

Methods: The study design was a descriptive qualitative study of HIV positive individuals receiving antiretroviral treatment. The study involved four focus group discussions with male and female participants at a tertiary center, city clinic, and rural church. We employed convenience sampling and invited patients coming for their routine visits and medication refills to participate.

Results: Participants had an awareness of both the direct and indirect effects of alcohol use. The direct effects related to the incompatibility of HIV medication and alcohol. The indirect effects related to the negative impact of alcohol on treatment adherence. Participants proffered reasons why HIV infected individuals on HIV treatment drink and felt that patients had to make a deliberate choice to stop drinking. Participants displayed some knowledge of interventions for drinking cessation and highlighted the use of pharmacological interventions to stop drinking. Participants indicated that they preferred HIV counselors to provide counseling services in view of the existing relationships that patients had with counselors.

Conclusion: People living with HIV have adequate knowledge of the effects of alcohol use in the context of HIV treatment. Stigma and the time taken to engage in an alcohol use intervention appeared to be the main impediments to uptake. The current model of HIV treatment, based on trust with the HIV care team, and maintenance of this trust, could bolster the uptake of an intervention. Involvement of HIV patients in their treatment is necessary to improve treatment outcomes in the context of alcohol use.

Keywords: alcohol use, HIV, impact, perceptions, Zimbabwe

\section{Introduction}

The advent of antiretroviral therapies has transformed HIV treatment and control, and HIV has become a chronic illness. ${ }^{1,2}$ The rate of new HIV infections in Zimbabwe is on the decline and mirrors a promising global picture with respect to longevity for HIV infected individuals. ${ }^{3,4}$ Behavioral change and advocacy have also proven to be key in HIV and AIDS care and control. ${ }^{5}$ However, alcohol use disorders (AUDs) are of major concern in the context of HIV and AIDS care. ${ }^{4,6,7}$ Evidence indicates that HIV infected individuals have a higher prevalence of AUDs than HIV negative individuals. ${ }^{8}$ Alcohol use is also associated with erratic treatment adherence. ${ }^{9}{ }^{10}$ In addition, HIV positive people suffer more physiologic harm from alcohol consumption, with increased cases of liver damage, in comparison to HIV negative individuals. ${ }^{11,12}$ 
Due to immunosuppression, patients with HIV who also have an AUD may suffer from concurrent medical conditions, such as TB, and consequently be on a variety of medications with a high pill burden, ${ }^{13}$ contributing to decreased adherence and resistance. ${ }^{14}$ In addition, pharmacological interventions may be unaffordable, particularly in low-income settings, with the only available treatments being psychosocial in nature. However, psychosocial interventions are sensitive to the "who, where, and what questions," and, as such, require an understanding of the lived experiences of the affected. . $^{15,16}$

Patients who receive HIV treatment are assessed and counseled for alcohol use as part of the pre-treatment work up in Zimbabwe. ${ }^{17}$ Patients who drink are defined as not operationally ready for antiretroviral treatment (ART) commencement ${ }^{17}$ and policy stipulates that HIV treatment cannot be commenced when there is evidence of alcohol use. ${ }^{17} \mathrm{~A}$ qualitative understanding of patient experiences and subjective expectations of treatment is important to inform the success of HIV and AUD programs. ${ }^{18}$ To this end, our study aimed to describe and understand the perceptions and impact of alcohol use in a sample of HIV positive individuals. The study was nested within an on-going, cluster randomized controlled trial of an AUD intervention. ${ }^{19}$

\section{Methods}

This study used a descriptive qualitative design to understand HIV infected individuals' perceptions ("who, why, and how") about alcohol use. ${ }^{20}$ Patients recruited into the study were already on ART after receipt of counseling and testing. Almost a third of the participants (30\%) had an AUD as defined by the Alcohol Use Disorders Identification Test (with a cutoff of 6 for females and 7 for males). ${ }^{21}$ In addition, we included participants who denied alcohol use to obtain their perspectives. In addition, data were collected through focus group discussions (FGDs) with people living with HIV/ AIDS (PLWHA) in order to obtain their perspectives on the status of care of HIV-infected individuals.

\section{Context and setting}

We obtained approval to undertake the study from the Medical Research Council of Zimbabwe (A/1936), Stellenbosch University Health Research Ethics Committee (SI14/10/222), the hospital ethics committees, and the Ministry of Health Permanent Secretary of Zimbabwe. The FGDs were held at an HIV clinic at a rural church-run hospital $(n=2)$, at a central hospital $(n=1)$, and at a city polyclinic $(n=1)$.

\section{Sampling strategy}

Convenience sampling was used. HIV infected patients, who had received a health education talk on adherence (as is standard practice and required for all) were informed of the study, and individually approached for consent. The health education talk consists of information on adherence to medication, the use of protection when engaging in sexual activity, signs and symptoms of opportunistic infections, abstention from alcohol and drug abuse, and good nutritional practices. Patients who agreed and gave written consent were assigned identifier numbers, which denoted their identities in the FGDs. Participants received \$3 (USD) as compensation.

\section{Data collection}

Data were collected between May and August 2015. A questionnaire was specifically developed for the FGDs. The FGDs were conducted in the local vernacular (Shona), audio recorded, and translated for analysis. The first two FGDs were of mixed gender (Table 1).

Trained facilitators who were conversant with the study moderated the FGDs. The training involved setting up the group, managing the group (such as dealing with dominating participants), administration of the questionnaire, understanding the content and context of the study, diary entries, and an approach to follow-up questions. Facilitators used questionnaires with initial prompts but then took their lead from participants. Data were derived from transcripts and analyzed using Atlas.ti. ${ }^{22}$

Table I Description of FGDs

\begin{tabular}{lllll}
\hline & FGD I & FGD2 & FGD3 & FGD4 \\
\hline $\begin{array}{l}\text { Venue } \\
\text { Participants }\end{array}$ & Central hospital & City clinic & Church-linked hospital & Church-linked hospital \\
$\mathrm{N}$ & 13 & 13 & 7 & 6 \\
$\quad \begin{array}{l}\text { Gender } \\
\text { Facilitators }\end{array}$ & Mixed & Mixed & Male & Female \\
$\mathrm{n}$ & 3 & 3 & 2 & 2 \\
$\quad$ Gender & $(2$ females, I male $)$ & $(2$ females, I male $)$ & $($ I male, I female $)$ & Female \\
\hline
\end{tabular}

Abbreviation: FGD, focus group discussion. 


\section{Data analysis}

Transcripts were read and coded by two independent reviewers and conflicts were resolved through discussion. Data from the transcripts were sorted and coded according to broad themes. Outputs from the transcripts were generated as a list of codes and quotations. Trained personnel identified, developed, and grouped emerging themes.

\section{Techniques to enhance reliability}

Triangulation, reflexivity, dependability, and conformability, as Guba's constructs, were adopted as tools to enhance reliability of the data obtained. ${ }^{23}$ Interviewers were from various fields, including nursing (BM-D, MK-U), psychiatry (MD, $\mathrm{MM}$ ), and linguistics (AP). In order to contain the subjective opinions of the interviewers, they worked in groups of three in each FGD.

\section{Results}

\section{Participants}

Thirty-nine patients participated in the FDGs. Their baseline demographic information is summarized in Table 2.

The major themes identified in the study included: 1) perceptions of the impact of alcohol use on HIV treatment; 2) participants' perceptions of HIV infected patients who drink alcohol; 3) fear and stigma; and 4) help and support. Table 3 summarizes the major themes and thematic areas.

\section{Perceptions of the impact of alcohol use on HIV treatment}

Participants perceived alcohol use to have both direct and indirect influences on HIV treatment.

\section{Alcohol use has a direct influence}

Participants perceived alcohol use to have a direct influence on HIV treatment, stating that "[...] drinking beer is not

Table 2 Participants' sociodemographic data

\begin{tabular}{ll}
\hline Sociodemographic data & N (\%) \\
\hline Gender & \\
$\quad$ Male & $23(59)$ \\
Female & $16(4 I)$ \\
Marital status & $27(69)$ \\
$\quad$ Married & $9(23)$ \\
Widowed & $2(5)$ \\
Single & $13(30)$ \\
Alcohol use disorder & Mean (SD) \\
\hline & $40(16.0)$ \\
\hline Age (years) & $10.65(3.68)$ \\
\hline Education (years in school) &
\end{tabular}

good because alcohol and medication are not compatible." [Participant 17, FGD2, M, 42y] and "drinking alcohol weakens the white blood cells. There will be competition between alcohol and medication." [Participant 24, FGD2, F, 48y] One participant also noted that on the "container of alcohol is written harmful. So alcohol is a drug on its own so drinking it would have meant that we are mixing various incompatible drugs." [Participant 7, FGD1, M, 35y] Thus, participants indicated awareness of the negative influence of alcohol, in and of itself, as well as alcohol's incompatibility with HIV medication. However, some participants perceived that: "It depends with the type of alcohol one has taken. Some will have drank kachasu [illicit brew], and other types are better." [Participant 6, FGD1, M, 36y] Another also mentioned the "[...] alcohol that is brewed in the villages in different types and several different things are added into the mixture." [Participant 4, FGD3, F, 43y] which is more intoxicating.

\section{Alcohol use has an indirect influence}

In addition to the direct negative effects of alcohol use on HIV treatment, participants also perceived that alcohol had indirect effects. Specifically, "[...] you can forget to take your medication when you are drunk." [Participant 10, FGD3, F, 39y] Similarly, "[...] you drink alcohol and get drunk, the first thing to happen is to forget the time to take your tablet." [Participant 5, FGD1, F, 44y]

Besides forgetting to drink your medication, or not drinking it at the correct time; when you: "[...] drink alcohol you end up forgetting to eat your sadza or eating food and you end up going to the beer hall." [Participant 28, FGD4, M, 47y] Thus, after "[...] drinking beer, the following morning one will have a hangover which causes one to lose appetite. Without eating food one cannot take the medication." [Participant 16, FGD2, F, 38y]

Lastly, drinking " $[\ldots]$ beer gives one confidence to indulge in bad things." [Participant 21, FGD2, M, 51y] More specifically, one " $[. .$.$] can engage in sexual activities without$ any protection because they cannot think properly because of being drunk." [Participant 1, FGD1, M, 45y] It should be noted, however, that "unprotected sex" was only mentioned as a risk in the mixed FGD. In the men-only FGD "unprotected sex" was not mentioned as a risk per se; instead, participants mentioned "[...] he would drink alcohol and end up taking prostitutes from the beer hall." [Participant 34, FGD4, M, 41y] Thus, the risk was considered to be associated more with "prostitutes" than with "unprotected sex". In contrast, in the women-only FGD group no reference was made to either "unprotected sex" or "prostitutes". 
Table 3 Major themes and thematic areas

\begin{tabular}{|c|c|c|}
\hline Major themes & Thematic area & Quote \\
\hline \multirow[t]{2}{*}{$\begin{array}{l}\text { Perceptions of alcohol } \\
\text { use in terms of HIV } \\
\text { treatment }\end{array}$} & $\begin{array}{l}\text { Alcohol use has a direct } \\
\text { influence }\end{array}$ & $\begin{array}{l}\text { "Drinking beer is not good because alcohol and medication are not compatible" } \\
\text { "Drinking alcohol weakens the body, there will be competition between alcohol and } \\
\text { medication" }\end{array}$ \\
\hline & $\begin{array}{l}\text { Alcohol has an indirect } \\
\text { influence }\end{array}$ & $\begin{array}{l}\text { "You can forget to take your medication" } \\
\text { "[...] drink alcohol you end up forgetting to eat your sadza [corn meal] or eating food } \\
\text { and you end up going to the beer hall" }\end{array}$ \\
\hline \multirow[t]{3}{*}{$\begin{array}{l}\text { Participant perceptions } \\
\text { of HIV infected } \\
\text { patients who drink } \\
\text { alcohol }\end{array}$} & $\begin{array}{l}\text { Some patients understood } \\
\text { the difficulty }\end{array}$ & $\begin{array}{l}\text { "[...] you feel sorry for them, so I feel this program should be done }[\ldots] \text { so that people } \\
\text { can stop taking alcohol" } \\
\text { "HIV infected patients who drink alcohol must be: "[...] asked why they continue to } \\
\text { drink }[\ldots][\text { it] may be stress about the home and families }[\ldots] \text { If they require any help } \\
\text { this can be forthcoming in order to relieve stress and stop falling in the trap of drinking } \\
\text { alcohol" }\end{array}$ \\
\hline & They cannot be helped & $\begin{array}{l}\text { "You [person drinking alcohol] are a difficult person who cannot be helped" } \\
\text { "[...] you don't listen and you are stubborn" } \\
\text { "[...] nurses should strongly threaten them [people drinking alcohol] with death" }\end{array}$ \\
\hline & $\begin{array}{l}\text { Other participants } \\
\text { acknowledged taking } \\
\text { responsibility }\end{array}$ & $\begin{array}{l}\text { "[...] to make a choice to either continue drinking beer or smoking and risk ending } \\
\text { your life }[\ldots] \text { it is all up to the patient" } \\
\text { "[...] you are told what is required and what is not required it's you[r] chance to } \\
\text { choose what you want, alcohol or tablets" }\end{array}$ \\
\hline Fear and stigma & & $\begin{array}{l}\text { "If the [health] workers are not free or approachable this creates barriers. If they are } \\
\text { free and friendly people can be helped. If they are not, people can be afraid to look for } \\
\text { help" } \\
\text { "You can hide the tablets from your friends thinking that they will laugh at you when in } \\
\text { actual fact taking tablets is important and you should tell your friends so that they can } \\
\text { remind you to take your tablets" }\end{array}$ \\
\hline \multirow[t]{4}{*}{$\begin{array}{l}\text { Help and support is } \\
\text { there }\end{array}$} & $\begin{array}{l}\text { Participants saw something } \\
\text { good in the AUD intervention }\end{array}$ & "[...] it is appropriate for people to be asked about the quantity of alcohol they drink" \\
\hline & Pills to stop drinking & $\begin{array}{l}\text { "There are pills to aid one in stopping drinking beer, let them be approved [...] some } \\
\text { people are no longer able on their own to stop drinking" } \\
\text { "As government institutions are generally lacking in terms of facilities, for example I } \\
\text { heard that at [hospital] there is a doctor who has a drug to completely stop someone } \\
\text { from drinking alcohol. So, sometimes such facilities are not yet there at government } \\
\text { hospitals" }\end{array}$ \\
\hline & Counselors are trusted & $\begin{array}{l}\text { "[...] but before that I should make use of the counselor information before I overload } \\
\text { the doctor with unnecessary work" } \\
\text { "[...] this is the work of counselors. Looking for help allover the place will cause risks } \\
\text { of misinformation and this is dangerous. It is important just to go to those who are } \\
\text { skilled to do the job" }\end{array}$ \\
\hline & Provide health education & $\begin{array}{l}\text { "[...] continuous health education from counselors }[\ldots] \text { Health education should be an } \\
\text { on-going process so that everyone [is] equipped with knowledge" } \\
\text { "I think counselors are more appropriate because they were skilled in approaching and } \\
\text { educating patients" }\end{array}$ \\
\hline
\end{tabular}

Abbreviation: AUD, alcohol use disorder.

\section{Participants' perceptions of HIV infected patients who drink alcohol}

Participants differed in their perceptions of HIV infected patients who drink alcohol whilst on HIV treatment.

\section{Understanding the difficulty}

Some participants appeared to have an understanding of the reasons for drinking and/or how difficult it was to stop drinking. Participant 41 said: "[...] you feel sorry for them, so I feel this program should be done $[\ldots]$ so that people can stop taking alcohol." [FGD3, F, 38y] Another stated that HIV infected patients who drink alcohol must be: "[...] asked why they continue to drink [...] [it] may be stress about the home and families [...] If they require any help this can be forthcoming in order to relieve stress and stop falling in the trap of drinking alcohol." [Participant 8, FGD1, F, 42y]

\section{They must take responsibility}

Others noted that it is the responsibility of the patient: "[...] to make a choice to either continue drinking beer or smoking 
and risk ending your life [...] it is all up to the patient." [Participant 8, FGD1, M, 43y] Similarly, Participant 36 said: "[...] you are told what is required and what is not required it's you[r] chance to choose what you want, alcohol or tablets." [FGD3, F, 37y] Others described how they: “[...] just accepted my status and chose to leave beer drinking." [Participant 22, FGD3, F, 37y]

\section{They cannot be helped}

Some participants, however, had a negative perception of those who drink alcohol whilst on treatment stating: "You [person drinking alcohol] are a difficult person who cannot be helped." [Participant 26, FGD2, F, 35y] Such a person can: "[...] get advice but it falls on deaf ears." [Participant 23, FGD2, F, 39y] "[...] you don't listen and you are stubborn." [Participant 42, FGD4, F, 41y] It was also stated that: “[...] drinking is a habit and not a disease." [Participant 11, FGD1, M, 43y] implying that a person has no excuse for not being able to stop drinking. One participant suggested: “[...] nurses should strongly threaten them [people drinking alcohol] with death.” [Participant 19, FGD2, M, 39y]

\section{Fear and stigma}

From the data, it was evident that fear was prevalent among participants. Fear may lead to non-disclosure: "One can be afraid to say that they are drinking alcohol." [Participant 38, FGD3, F, 47y] Similarly, Participant 8 said: "If the [health] workers are not free or approachable this creates barriers. If they are free and friendly people can be helped. If they are not, people can be afraid to look for help." [FGD1, F. 49y] Participants also said that there was a lot of stigma associated with HIV which made disclosure to drinking partners difficult: "You can hide the tablets from your friends thinking that they will laugh at you when in actual fact taking tablets is important and you should tell your friends so that they can remind you to take your tablets." [Participant 28, FGD4, M, 36y]

\section{There is help and support}

In general, participants perceived an AUD intervention program, and screening patients for alcohol use, to be good. Participants mentioned: "[...] it is appropriate for people to be asked about the quantity of alcohol they drink." [Participant 8, FGD1, M, 43y] They also mentioned strategies that they perceived would be helpful for patients who needed them.

\section{Pills to stop drinking}

One participant mentioned that if " [...] there are pills to aid one in stopping drinking beer, let them be approved [...] some people are no longer able on their own to stop drinking." [Participant 25, FGD2, M, 44y] Similarly, another stated:

As government institutions are generally lacking in terms of facilities, for example I heard that at [hospital] there is a doctor who has a drug to completely stop someone from drinking alcohol. So, sometimes such facilities are not yet there at government hospitals. [Participant 9, FGD1, F 37y]

\section{Counselors are trusted}

Participants thought that counselors could be trusted and should be approached first for help: "But before that I should make use of the counselor information before I overload the doctor with unnecessary work." [Participant 11, FGD1, M 31y] Participant 9 responded that he was in agreement: “[ ...] this is the work of counselors. Looking for help all over the place will cause risks of misinformation and this is dangerous. It is important just to go to those who are skilled to do the job." [FGD1, M, 39y]

Additionally, it appeared as if fear of health workers assisted some of the participants to stop drinking alcohol: "Some don't drink the beer because they fear for their health and the health workers." [Participant 20, FGD2, M, 37y]

\section{Provide health education}

Another form of help identified included "[...] continuous health education from counselors [...] Health education should be an on-going process so that everyone [is] equipped with knowledge." [Participant 17, FGD2, F, 41y] Counselors were especially trusted to provide this education: "I think counselors are more appropriate because they were skilled in approaching and educating patients." [Participant 3, FGD1, M, 35y]

\section{Discussion}

This study aimed to understand patients' perceptions of the impact of alcohol use in the context of HIV care. Participants perceived alcohol use to have both direct and indirect effects on HIV treatment. Stigma and fear about their ability to access treatment in the event that they disclose their HIV status were some of the barriers to receiving care for AUDs. However, participants were receptive to the offer of treatment for AUDs. Interventions for AUDs in the context of HIV should, therefore, be developed.

\section{Perceptions of AUDs in the context of HIV treatment}

Participants understood that alcohol use is a challenge in the context of HIV infection and treatment. They were aware of 
the direct and indirect effects of alcohol use on HIV treatment. A direct effect described was the incompatibility of alcohol use with HIV treatment. An indirect effect was nonadherence to medication when using alcohol. The belief that alcohol use was not compatible with ART has been described in research in Sub-Saharan Africa. ${ }^{24}$ Kalichman et al documented planned omission of ART if patients were going to drink, fearing toxicity of mixing alcohol and HIV treatment. ${ }^{25}$

\section{Participants' perceptions of HIV infected patients who drink alcohol}

The participants were of the opinion that they could not take medication while drinking beer. This implied that they perceived that alcohol would either interact negatively with medication, or the staff would not dispense medication as long as they were known to drink. As the health education session is given before the commencement of ART, this to many patients means that ART and HIV are incompatible and can lead to death. HIV and AUDs health education messages need to be clear to avoid wrong interpretations by patients. The Kalichman et al study indicated deliberate skipping of medication by patients with AUDs due to beliefs of incompatibility of alcohol and HIV treatment. ${ }^{26}$ This highlights the need to train counseling staff on the impact of, and treatment for, co-occurring HIV and AUDs.

\section{Fear and stigma}

Stigma related to mental and AUDs is a major impediment and several studies have found it to be a particularly challenging barrier to seeking treatment or adhering to treatment. ${ }^{27,28}$ Stigma has to be addressed at individual, community, and programmatic levels. Improving disclosure could translate into better adherence and improved support for HIV infected individuals with problematic alcohol use. ${ }^{29}$

Participants noted that both HIV treatment and alcohol use are stigmatized. This prevented them from disclosing both their HIV status and drinking. Hospital and clinic staff often delay antiretroviral treatment initiation once they discover that patients have an alcohol use problem, as required by the Zimbabwe National Operational Guide. ${ }^{17}$ This may underlie the negativity displayed by participants in the study as the messages passed on by staff are also supported by national guidelines. This is despite the fact that the same guidelines used for commencing HIV treatment do not include treatment for AUDs. This is underscored by another study which indicated that fear of being discriminated against (due to drinking habits) by HIV counselors and nursing staff was a barrier to seeking help. ${ }^{30}$

\section{There is help and support}

In terms of the management of alcohol related problems, participants appeared to prefer pharmacological approaches. With respect to psychosocial interventions, participants favored primary care counselors as the agents of change, citing existing relationships with the counselors. Participants welcomed the use of health education to deal with alcohol use problems in the context of HIV treatment. For patients who have alcohol dependency, there may be a need for referral to specialist care that may include pharmacological interventions. In patients where there is high non-adherence to treatment and increased pill burden, monthly depot naltrexone may be a preferred treatment. ${ }^{31,32}$

The level of knowledge displayed by participants of the link between HIV treatment and alcohol use was high. This knowledge can be exploited to address alcohol use in the context of HIV treatment. It is notable that while nurses and primary care counselors have invested in educating patients on the impediments to optimum HIV care, educational information is presented in a negative way that may dissuade participants from opening up about their problems, including alcohol use. Thus, similar to observations made by previous studies, there is a need to train staff in counseling skills through refresher courses. ${ }^{33}$

\section{AUD interventions}

This study shows the challenges that HIV care staff face in dealing with dual diagnosis patients in Zimbabwe. If patients are not commenced on ART as a result of an alcohol use history, delays will inevitably lead to poorer outcomes. Studies have shown that brief interventions can be effective in reducing AUDs. Appropriate health education on the assessment and treatment of HIV and AUDs is imperative in HIV treatment settings. Lack of trained personnel, lack of time, and an unmotivated work force may be barriers. However, task sharing using nurses, general medical staff, and peer or lay-counselors may cover that gap. Use of manuals may be used to improve fidelity to treatment.

Zimbabwe has no separate nor embedded AUD treatment program for HIV infected individuals. Further, due to the prevailing economic situation, the cost of pharmacological agents for AUDs have been beyond the reach of the HIV infected individuals. However, from the study, it appears that there was limited use of pharmacological agents. This may need to be scaled up.

However, in the development of the interventions, given the seeming power of health staff over patients, resources need to be invested in developing the motivational skills of 
staff so they appreciate the collaborative and integrated treatment approach that is required. This needs to be coupled with helping patients understand that the receipt of treatment is a right. Human rights training needs to be embedded in the training of health workers as well.

Systematic reviews have shown that Screening and Brief Referral Interventions(SBRITs) are helpful in reducing AUDs in the general population without HIV infection despite requiring specific adjustments to suit patients, the professionals, and the characteristics of the organization. ${ }^{34}$ Brown et al showed in a narrative review that the interventions were able to reduce alcohol use in HIV infected individuals, but called for studies that isolate the effective components of the interventions. ${ }^{35}$ Although HIV infected patients are already on many treatments, some with alcohol dependency may require pharmacological interventions to improve both HIV and AUD outcomes. ${ }^{36} \mathrm{~A}$ number of trials to integrate AUDs in HIV care settings are on-going. ${ }^{37}$ Some of the findings in this study can inform the design of future trials, for example taking gender into account as single-gender groups in this setting may help to optimize participation in behavioral interventions.

The need for SBRITs is highlighted in this study with participants calling for both behavioral and pharmacological interventions. The preferred staff to offer this intervention are the primary care counselors and nurses. This has been shown to be feasible in the management of other conditions, including TB and HIV. ${ }^{38}$ Lay health workers have been successfully recruited to offer community-based treatment for common mental disorders in Zimbabwe. ${ }^{39}$ The content should include motivational "talk" delivered in an empathetic manner, with a non-judgmental attitude and stigma reduction. There is also a need to obtain buy-in from policy makers for the integration of HIV and AUD treatments.

\section{Limitations}

These findings should be interpreted with a number of limitations in mind. First, as the FGDs were used to gather information, contributory effects of "group think" and "group polarization" may have influenced responses to questions. ${ }^{40}$

Second, alcohol use in HIV is a sensitive area of enquiry, especially given that patients may be disallowed HIV treatment initiation unless they discontinue drinking. This may have fed into the negative views that participants had of drinking whilst on ART.

Third, the presence of the nurse who gave a health education talk to the group before the FDG may have prompted some participants to respond more favorably than they would otherwise have done. This FGD was in a church related hospital where morality issues are important. The view in this community is that women should not drink and HIV is transmitted due to "bad morals". This may have influenced participants' responses. The women, therefore, shied away from talking about prostitution and unprotected sex. Most of the participants were married women who might have acquired HIV from a partner and/or through unwanted sex. It is recommended that future researchers are cognizant of the fact that the venue where FDGs are conducted may have an influence on participants' responses.

Finally, it became evident that participants were not able to express themselves freely owing to the mixed gender status of the FGDs, as in Zimbabwe it is viewed as culturally inappropriate for women to drink and drinking among women is associated with commercial sex work. Consequently, one "female only", and one "male only" FGDs were conducted.

\section{Acknowledgments}

The principal researcher is a clinical psychiatrist (MM) pursuing doctoral studies. Whilst he did not know the participants prior to the FGD, he is involved in the care of PLWHA. ASJ $\mathrm{vd} \mathrm{W}$ is a psychiatric researcher with an MA in psychology by thesis qualification. BM is a psychiatric nurse practitioner and lecturer with an MPhil, who is not involved in the care of PLWHA. However, the study participants may have been receiving care from nurses and do share with them confidential information. MD is a psychiatrist trained in the World Health Organization Mental Health Cap Action Programme (WHO mhGAP) intervention guide and participates in the care of PLWHA, albeit not this particular group. MKU is a nurse with a Masters Level qualification. AP is a researcher who specializes in adult education and has no contact with these participants or any similar group other than the informal contact. $\mathrm{DC}$ is a researcher/psychiatrist with a $\mathrm{PhD}$ who has contact with patients similar to this study population. SR is a professor in public health and has no contact with this group of patients. SS is a distinguished professor of psychiatry and senior researcher on the project which interacts with patients similar to this sample, but has no contact with this study sample.

\section{Author contributions}

$\mathrm{MM}$ is the principal researcher. $\mathrm{MM}$ and SS were involved in the conception and development of the study protocol. SR, SS and $\mathrm{DC}$ were involved in developing the methodology. AP, MD, $\mathrm{BM}, \mathrm{MKU}$, and MM were involved in focus groups. SS, SR, DS and DC had no contact with participants. MM and ASJ vd W drafted the first version of the manuscript. All authors 
contributed toward data analysis, drafting and revising the paper and agree to be accountable for all aspects of the work.

\section{Disclosure}

The authors report no conflicts of interest in this work.

\section{References}

1. Tao LL, Liu M, Li SM, et al. Impact of antiretroviral therapy on the spread of Human Immunodeficiency Virus in Chaoyang District, Beijing, China: using the Asian epidemic model. Chin Med J (Engl). 2017;130(1):32-38.

2. Sashindran VK, Chauhan R. Antiretroviral therapy: shifting sands. Med J Armed Forces India. 2016;72(1):54-60.

3. Lopman B, Nyamukapa C, Mushati P, Mupambireyi Z, Mason P, Garnett GP, Gregson S. HIV incidence in 3 years of follow-up of a Zimbabwe cohort--1998-2000 to 2001-03: contributions of proximate and underlying determinants to transmission. Int J Epidemiol. 2008;37(1):88-105.

4. CBD 2015 HIV Collaborators. Estimates of global, regional, and national incidence, prevalence, and mortality of HIV, 1980-2015: the Global Burden of Disease Study 2015. Lancet HIV. 2016;3(8):e361-387.

5. Sunguya BF, Munisamy M, Pongpanich S, Yasuoka J, Jimba M. Ability of HIV advocacy to modify behavioral norms and treatment impact: a systematic review. Am J Public Health. 2016;106(8):e1-8.

6. Justice AC, Lasky E, McGinnis KA, et al. Medical disease and alcohol use among veterans with human immunodeficiency infection: A comparison of disease measurement strategies. Med Care. 2006;44(8 Suppl 2):S52-60.

7. Williams EC, Hahn JA, Saitz R, Bryant K, Lira MC, Samet JH. Alcohol use and Human Immunodeficiency Virus (HIV) infection: current knowledge, implications, and future directions. Alcohol Clin Exp Res. 2016;40(10):2056-2072.

8. Galvan FH, Bing EG, Fleishman JA, et al. The prevalence of alcohol consumption and heavy drinking among people with HIV in the United States: results from the HIV Cost and Services Utilization Study. J Stud Alcohol. 2002;63(2):179-186.

9. Azar MM, Springer SA, Meyer JP, Altice FL. A systematic review of the impact of alcohol use disorders on HIV treatment outcomes, adherence to antiretroviral therapy and health care utilization. Drug Alcohol Depend. 2010;112(3):178-193.

10. Braithwaite RS, Conigliaro J, Roberts MS, et al. Estimating the impact of alcohol consumption on survival for HIV+ individuals. AIDS Care. 2007;19(4):459-466.

11. Justice AC, McGinnis KA, Tate JP, et al. Risk of mortality and physiologic injury evident with lower alcohol exposure among HIV infected compared with uninfected men. Drug Alcohol Depend. 2016;161:95-103.

12. Braithwaite RS, Conigliaro J, McGinnis KA, Maisto SA, Bryant K, Justice AC. Adjusting alcohol quantity for mean consumption and intoxication threshold improves prediction of nonadherence in HIV patients and HIV-negative controls. Alcohol Clin Exp Res. 2008;32(9):1645-1651.

13. Swaminathan S, Nagendran G. HIV and tuberculosis in India. J Biosci. 2008;33(4):527-537.

14. Claborn KR, Meier E, Miller MB, Leffingwell TR. A systematic review of treatment fatigue among $\mathrm{HIV}$-infected patients prescribed antiretroviral therapy. Psychol Health Med. 2015;20(3):255-265.

15. Neergaard MA, Olesen F, Andersen RS, Sondergaard J. Qualitative description - the poor cousin of health research? BMC Med Res Methodol. 2009;9:52.

16. Milne J, Oberle K. Enhancing rigor in qualitative description: a case study. J Wound Ostomy Continence Nurs. 2005;32(6):413-420.

17. AIDS \& TB Programme MoHaCC, Zimbabwe. OPERATIONAL AND SERVICE DELIVERY MANUAL FOR THE PREVENTION, CARE AND TREATMENT OF HIV IN ZIMBABWE. Zimbabwe: MoHaCC; 2017. Available from: http://ophid.org/treat-all-toolkit/MOHCC $\% 20$ Guidelines/MOHCC\%20Zimbabwe\%20OSDM\%202017.pdf. Accessed January 25, 2018.
18. Gustavsson S, Gremyr I, Kenne Sarenmalm E. Designing quality of care--contributions from parents: Parents' experiences of care processes in paediatric care and their contribution to improvements of the care process in collaboration with healthcare professionals. J Clin Nurs. 2016;25(5-6):742-751.

19. Madhombiro M, Dube-Marimbe B, Dube M, et al. A cluster randomised controlled trial protocol of an adapted intervention for alcohol use disorders in people living with HIV and AIDS: impact on alcohol use, general functional ability, quality of life and adherence to HAART. BMC Psychiatry. 2017;17(1):44.

20. McBain L, Donnelly S, Hilder J, O’Leary C, McKinlay E. "I wanted to communicate my feelings freely": a descriptive study of creative responses to enhance reflection in palliative medicine education. $B M C$ Med Educ. 2015;15:180.

21. Perula-de Torres LA, Fernandez-Garcia JA, Arias-Vega R, MurielPalomino M, Marquez-Rebollo E, Ruiz-Moral R. [Validity of AUDIT test for detection of disorders related with alcohol consumption in women]. Med Clin (Barc). 2005;125(19):727-730. Spanish.

22. atlasti.com [homepage on the Internet]. Qualitative data analysis. Atlas. ti Scientific Software Development GmbH; 2016. Available from: http:// atlasti.com/. Accessed January 25, 2018.

23. Hamberg K, Johansson E, Lindgren G, Westman G. Scientific rigour in qualitative research--examples from a study of women's health in family practice. Fam Pract. 1994;11(2):176-181.

24. Fatch R, Emenyonu NI, Muyindike W, Kekibiina A, Woolf-King S, Hahn JA. Alcohol Interactive Toxicity Beliefs and ART Non-adherence Among HIV-Infected Current Drinkers in Mbarara, Uganda. AIDS Behav. 2017;21(7):1812-1824.

25. Kalichman SC, Kalichman MO, Cherry C, et al. Intentional Medication Nonadherence Because of Interactive Toxicity Beliefs Among HIV-Positive Active Drug Users. J Acquir Immune Defic Syndr. 2015;70(5):503-509.

26. Kalichman SC, Amaral CM, White D, et al. Prevalence and clinical implications of interactive toxicity beliefs regarding mixing alcohol and antiretroviral therapies among people living with HIV/AIDS. AIDS Patient Care STDS. 2009;23(6):449-454.

27. Alexandra Marshall S, Brewington KM, Kathryn Allison M, Haynes TF, Zaller ND. Measuring HIV-related stigma among healthcare providers: a systematic review. AIDS Care. 2017;29(11):1337-1345.

28. Heestermans T, Browne JL, Aitken SC, Vervoort SC, KlipsteinGrobusch K. Determinants of adherence to antiretroviral therapy among HIV-positive adults in sub-Saharan Africa: a systematic review. BMJ Glob Health. 2016;1(4):e000125.

29. Yadav UN, Chandrasekharan V, Guddattu V, Gruiskens J. Mixed method approach for determining factors associated with late presentation to HIV/AIDS care in southern India. J Postgrad Med. 2016;62(3):173-177.

30. Kekwaletswe CT, Morojele NK. Patterns and predictors of antiretroviral therapy use among alcohol drinkers at HIV clinics in Tshwane, South Africa. AIDS Care. 2014;26 Suppl 1:S78-82.

31. Hartung DM, McCarty D, Fu R, Wiest K, Chalk M, Gastfriend DR. Extended-release naltrexone for alcohol and opioid dependence: a meta-analysis of healthcare utilization studies. J Subst Abuse Treat. 2014;47(2):113-121.

32. Gastfriend DR. Intramuscular extended-release naltrexone: current evidence. Ann N Y Acad Sci. 2011;1216:144-166.

33. Ross MW. Factors affecting information and education, and behaviour change. AIDS Care. 1991;3(4):419-421.

34. Keurhorst M, van de Glind I, Bitarello do Amaral-Sabadini M, et al. Implementation strategies to enhance management of heavy alcohol consumption in primary health care: a meta-analysis. Addiction. 2015;110(12):1877-1900.

35. Brown JL, DeMartini KS, Sales JM, Swartzendruber AL, DiClemente RJ. Interventions to reduce alcohol use among HIV-infected individuals: a review and critique of the literature. Curr HIV/AIDS Rep. 2013;10(4):356-370.

36. Edelman EJ, Maisto SA, Hansen NB, et al. The Starting Treatment for Ethanol in Primary care Trials (STEP Trials): protocol for three parallel multi-site stepped care effectiveness studies for unhealthy alcohol use in HIV-positive patients. Contemp Clin Trials. 2017;52:80-90. 
37. Parry CD, Morojele NK, Myers BJ, et al. Efficacy of an alcohol-focused intervention for improving adherence to antiretroviral therapy (ART) and HIV treatment outcomes - a randomised controlled trial protocol. BMC Infect Dis. 2014;14:500.

38. Fairall L, Bachmann MO, Lombard C, et al. Task shifting of antiretroviral treatment from doctors to primary-care nurses in South Africa (STRETCH): a pragmatic, parallel, cluster-randomised trial. Lancet. 2012;380(9845):889-898.
39. Chibanda D, Bowers T, Verhey R, Rusakaniko S, Abas M, Weiss HA, Araya R. The Friendship Bench programme: a cluster randomised controlled trial of a brief psychological intervention for common mental disorders delivered by lay health workers in Zimbabwe. Int J Ment Health Syst. 2015;9:21.

40. Robins SP, Judge TA. Organizational behavior (14th ed.). Hoboken, NJ: Pearson. 2011
HIV/AIDS - Research and Palliative Care

\section{Publish your work in this journal}

HIV/AIDS - Research and Palliative Care is an international, peerreviewed open access journal focusing on advances in research in HIV its clinical progression and management options including antiviral treatment, palliative care and public healthcare policies to control viral spread. The journal is included in PubMed. The manuscript man-

\section{Dovepress}

agement system is completely online and includes a very quick and fair peer-review system, which is all easy to use. Visit http://www.dovepress. $\mathrm{com} /$ testimonials.php to read real quotes from published authors. 